\title{
Four Factors that will shape the Future of Work
}

\author{
Michal Beno, City University of Seattle, United States
}

\begin{abstract}
The future of work is shaped by technological progress, globalisation and glocalisation, and societal and institutional change. As a result of recent developments, a diverse world of work with significant differences in working conditions by industry and occupation will develop, with a focus on creative, interactive and more complex activities with essential skills. At the same time, demands on companies with regard to innovation and flexibility are growing. To understand the future of work, we believe it is essential to explore four major factors that will impact on the future of work: 1) Technological progress, IT platforms, the sharing and knowledge economy; 2) Demographic, social and environmental changes; 3) Globalisation and glocalisation; and 4) Labour flexibility. Our aim is to gain a better understanding of the dynamics of the future of work by examining these four key factors that influence today's labour market, because this market is agile, since people can work anywhere at any time. In summary, seeing automation as synonymous with job losses is not correct. We contend that it is a mistake to believe that globalisation and technological advances lead to a reduction in the demand for human employees. However, it is possible that the opposing viewpoints of those who agree and those who disagree with this opinion are causing a polarisation of the workforce. Changes in our society, such as the constantly evolving demography, as well as environmental issues and ICT, have an influence on the way we work, and when, how and where we work.
\end{abstract}

Keywords-future of work, four major impacting factors, labour market.

\section{INTRODUCTION}

Clearly we are living in a world of fundamental transformation in the way that employers and employees work. Work is not only an integral part of our lives, but also one of the most important topics of human concern throughout the world [1-4]. Today's labour markets are undergoing a primary change and are facing less of a job crisis than a work revolution [5].

The debate on the future of work is increasing in line with the growth of critical opinions and possible opportunities arising from robotics, algorithms and automation [6-7] in political and economic spheres worldwide. This means that technology and the future of work are becoming more important by the day as the situation is regularly confronted by modern breakthroughs.

Michal Beno, VSM/City University of Seattle, 85104 Bratislava, Slovakia, e-mail: michal.beno@vsm-student.sk.

The original paper was published in the WorldCist2019 conference proceedings.
When many factors work together and the future of a complex system depends on multiple actors, there is never just one possible future. This has also been reflected in discussions on the future of work since the publication of the studies by Frey and Osborne [8-10]. The central questions raised by this approach are: What kind of future do human beings want? And how can human beings act accordingly? The goal is not to make fixed predictions, but to identify new options for today's situation. It becomes more important to understand what the main drivers of development are and to find new solution perspectives. It is a matter of identifying and formulating open questions rather than accurately forecasting the job market and the future of work.

In this paper, we will outline four very different factors that will have implications for the world of work: 1) Technological progress and the sharing economy; 2) Demographic, social and environmental changes; 3) Globalisation and glocalisation; and 4) Labour flexibility. The impact of these on the future of work cannot be ignored by governments, organisations or individuals, as we are living through an essential transformation in the way we work. Automation and thinking machines are replacing human tasks and jobs. The resultant changed demographic trends and consumption have been causing environmental degradation. Continuing globalisation has a major influence on work, working conditions and work security all over our connected world. Thus the nature of work has changed, and this includes more flexible work anywhere and at any time. According to the latest data, the world's unemployment rate has dropped to $5 \%$, the lowest level since the global crisis of 2008 [11].

This paper is based on a robust, evidence-based approach including key elements such as a comprehensive literature review and full analysis of trends and disruptions. In our study, we carried out a detailed literature analysis of publications related to the future of work. Drawing on this analysis, the four factors were explored systematically. Our aim is to gain a better understanding of the dynamics of future work and to illustrate the role of these four key factors that influence today's labour market, because this market is agile and people can work anywhere at any time.

\section{THE FOUR MAJOR IMPACTING FACTORS}

The greatest challenge in understanding the future of work lies in identifying the underlying implications for the four chosen factors and in understanding the roles played by these factors. Under ideal circumstances, all the parties involved 
(the individual, businesses and other employers, social and governmental institutions) will recognise the fundamental evolution in the nature of work. In this section, we review the major components that collectively constitute the future of work. On the basis of our experience and the literature review, we have identified four major impacting factors that shape and influence the nature of future work and the future workforce. These momentous changes raise huge organisational and social challenges, pose problems for the requisite human talent, and will result in risk, disruption and political and social revolution. Our preview describes the main factors that will influence thinking about many possible scenarios that could develop for the future of work.

\section{A. Technological progress, IT platforms, the sharing and knowledge economy}

More and more tasks can be done by machines. The key drivers of this change are rapid, sustained technological advances under the spread of digitisation affecting nearly all occupational groups. Technological advances like automation, robotics, AI, sensors and data have created entirely new ways of getting work done. By 2025, machines will do more work than humans, according to the latest report [12]. This technological transformation of the nature of the workforce and also of organisations has led to a redesigning of most jobs. If employees are able to adapt, the robot revolution need not cause fear, and machines will continue to work for human beings.

Human beings envisage automation as being a situation in which a machine is brought in as a substitute for human labour, e.g. autonomous vehicles, delivery drones. Initially, automation focused on routine tasks, such as clerical work, bookkeeping, basic paralegal work and reporting. With modern technological advances and ever-increasing computing power (in other words, the digital revolution), it is now also increasingly likely that non-routine tasks will become automated [13]. Mandl et al. [14] emphasise that "cooperation among self-employed workers and SMEs is a traditional way of doing business to overcome the limitations".

Frey and Osborne [9] forecast that within a few decades many occupations will disappear in the face of new means of production. Gruen [15] states that "automation tends to take jobs but the invention of new complex tasks creates new jobs". As far as we know, technology is leading to the disappearance of jobs, but only technology can save them. This confirms the report by the McKinsey Global Institute [16], which predicts that by 2030 as many as 800 million jobs could be lost to automation worldwide. The report also states that, as in the past, technology will not have a purely negative impact on jobs, but new jobs will also be created. Nübler [17] recognises that technological change is non-linear, uncertain and a complex process that comes in waves, thereby driving jobdestruction and job-creation at the same time. These phases do not happen automatically, but are brought about by a variety of forces at the economic, societal and political levels. Furthermore, the study says that advances in AI and robotics will have a drastic effect on everyday working lives [16]. We believe that jobs will not disappear entirely, but many will be redefined. Considering automation to be synonymous with job losses is not correct. Ford [18] explains that the job positions facing the most risk are those which "are on some level routine, repetitive and predictable". There is a high probability of automation for jobs like cashiers, counter and rental clerks, and telemarketers [9]. According to the report by Deloitte [19], there is a high likelihood that over 100000 jobs in the legal sector could be automated. Occupations at least risk of automation include recreational therapists, first-line supervisors of mechanics, installers, repairers, occupational therapists and healthcare social workers [9], in other words those where there is a close relationships with clients.

Part of the technological change in work is linked to IT platforms. Sharing-economy platforms have fostered competition and redefined industry boundaries in a range of businesses [20] and workplaces. We divide the evolution of the sharing economy into three phases: 1) communication (e.g. Yahoo, Aol); 2) Web 2.0 and social media (e.g. Google, Facebook, Twitter); and 3) the sharing economy. Sharingeconomy workers drive you home, deliver groceries and office lunches or rent your home.

According to Stephany [21], sharing economy can be a confusing term. In practice, various definitions of this term are found, e.g. gig economy or on-demand economy, collaborative economy, access economy, peer-to-peer economy [22-23]. Stephany [21] has provided a concise definition with five main limbs: "The sharing economy is the value in taking underutilised assets and making them accessible online to a community, leading to a reduced need for ownership of those assets." We believe that the sharing economy will experience significant growth in the future.

Employment in the knowledge-based economy is characterised by an increasing demand for more highly-skilled workers [25]. Powell and Snellman [26] define the knowledge economy as "production and services based on knowledgeintensive activities that contribute to an accelerated pace of technical and scientific advance, as well as rapid obsolescence. The key component of a knowledge economy is a greater reliance on intellectual capabilities than on physical inputs or natural resources."

\section{B. Demographic, social and environmental changes}

Needs and demands for goods and services have undergone a transformation worldwide. The total world population in August 2018 was in excess of 7.63 billion people [27], and the trend is upward [28]. According to the available data, China is the most populous country, with more than 1.4 billion people, followed by India with 1.355 billion [27]. With figures like these to contend with, it is essential for consumption by the population and natural resources to be monitored. Furthermore, all EU28 states are to a greater or lesser extent already affected by demographic change, with ageing populations and a shrinking potential domestic workforce.

As stated by the Technology at Work v2.0 report [29], the working age population in industrial countries peaked at 388 million in 2011, with the expectation of a decline by 30 
million by 2030. Growth in working age populations for industrial countries has slowed from $1 \%$ per year for the period $1970-90$ to $0.4 \%$ per year for $1990-2010$, and the figure is expected to fall by $0.3 \%$ per year over the next 20 years. Growth in human capital may also slow. These authors believe that automation could pose more risks to jobs than demographic changes. But we assume that demographic change, imploding birth rates and the ageing society have rapidly moved to the centre of public debate worldwide. Naturally, the baby boomers are now reaching retirement age, and we are seeing greater labour mobilisation on the labour market, including women, older workers, immigration and the allocation of workers to areas of dynamic labour demand. Buck et al. [30] highlight the following national/international factors relating to work development: birth rates, the timing of births, family and household composition, age structure of the total population and of the labour force, labour force participation and employment rates among various groups of people, definition of working age population, and normal and early retirement.

Movement of social values and behaviour creates new market spaces. Changes in the way we work have led to the expansion of various business ideas, in combination with social and health issues. Grantham [31] stresses the change in the approach to workplace design and the move from costbased measures of building performance to more humancentric behavioural measures of wellness and well-being. This is confirmed by the growing global interest in this topic. For example, the United Nations [32] has placed Good Health and Well-being in the third place of the target list of 17 development goals by 2030. Maintaining a healthy and productive workforce remains a current priority, and is more demanding nowadays in the context of changes in organisations and the environment [33].

In the literature, it is stated that humans or human capital can offer companies a competitive advantage [34-36]. Schleicher [37] suggests that "knowledge is no longer stacked up in silos. What is required is the capacity to think across disciplines, connect ideas and 'construct information': these 'global competencies' will shape our world and the way we work and live together." Diversity of the workforce brings a strategic marketplace advantage to the workplace, as stated by Hunt et al. [38]. Managing populations of people in different age, gender, ethnicity and cultural groups brings a greater understanding of how different people collaborate to work together.

One of the major challenges facing organisations at present is to transform the culture of the organisation to fulfil new business realities and imbue employees with a sense of changing values [39]. Therefore those organisations that are able to complete this cultural transformation successfully and utilise the knowledge, skills and abilities of the employees will have a great advantage over those that fail to do so. Yet many organisations that try to carry out this transformation of culture are often unsuccessful. One of the possible reasons for this is that the motivations, needs and interests of employees differ according to the generation they are born in [40]. For this reason, Blattner and Walter [41] highlight the need to create a deep, engaging and highly efficient organisational culture that integrates the power of several generations and offers employees the opportunity to use their own talents and skills. These generations include those of veterans (born in 1922-1945), baby boomers (1946-1964), generation X (1965-1980), generation Y (millennials, 1981-2000) and, lastly, generation $\mathbf{Z}$ (1995-2012).

The effects of climate change are not highly apparent in the everyday life of the current generation, but its consequences are increasingly noticeable across continents. . The growing worldwide awareness of the consequences of climate change, especially in the poorest countries, leads for example to high migration if people's livelihoods are put in danger by natural disasters. This migration will have consequences for the domestic workforce of countries if their numbers are supplemented by such migrant workers. There is a strong consensus among the scientific community that the earth is warming and that this is caused by human $\mathrm{CO}_{2}$ emissions. From our perspective, changing weather patterns significantly affect economic activity. All sectors should therefore prepare to face a range of new threats and opportunities, including cooperation. As reported by the OECD [42], the world economy is projected to nearly quadruple by 2050 , with a growing demand for energy and natural resources as a result. Global greenhouse gas (GHG) emissions are expected to increase by $50 \%$, primarily due to a $70 \%$ growth in energy-related $\mathrm{CO}_{2}$.

\section{Globalisation and glocalisation}

We are of the opinion that globalisation has four key characteristics: Globalisation is an unstoppable force, it has winners and losers, national identities and local industries are unique, and it leads to global economic integration. Globalisation, which has been the key force in our labour market, was and still is badly managed. After the first wave of this process, there remained a large group of insufficiently qualified people. In the second wave of globalisation, qualified people with significant specialisation skills were also affected.

Huws et al. [43] emphasise that there is a growing awareness that the globalisation process is playing an increasingly important role in shaping work patterns. In the era of globalisation, most economists and policymakers have asserted that trade liberalisation has a strong potential to contribute to growth and that those effects will be beneficial to employment. This belief has strongly influenced the liberalisation policies of the past 25 years in multilateral, regional and bilateral settings. Yet evidence from surveys illustrates that negative perceptions of the labour-market effects of trade are frequent and persistent among the population, particularly in the industrialised world, but increasingly also in developing countries. Recent surveys show a rising concern about income and job security [44], although there are no indications that the interviewees had negative perceptions of globalisation. We feel that most people believe in the positive growth effects of globalisation, as is also shown by McKeon's [45] claims that this process 
has obliterated trade barriers, narrowed income gaps and bolstered economic co-operation among nations.

The definition of globalisation is a source of contention among scholars across the social sciences. This term became popular in the last decade of 20th century, although the phenomenon itself is actually much older, with periods of globalisation in the 16th and 19th centuries. Current globalisation is marked by several phenomena occurring at the same time: new markets linked globally operating 24 hours a day; new technological tools; new actors, such as multinational corporations, global networks of nongovernmental organisations (NGOs) and other groups transcending national boundaries; and new international rules increasingly binding national governments and reducing the scope for national policy. Globalisation is not so much driven by technological progress, but is rather the outcome of political and ideological change. It is a human-led (or rather state-led) process [46].

OECD [47] defines globalisation as "generally used to describe an increasing internationalisation of markets for goods and services, the means of production, financial systems, competition, corporations, technology and industries. Amongst other things this gives rise to increased mobility of capital, faster propagation of technological innovations and an increasing interdependency and uniformity of national markets." We understand this term generally as a process of creating a worldwide network of business and markets. This causes greater mobility of goods, services, capital and workforces around the world. The process is made possible through the rapidly decreasing cost of ICT.

It is argued that globalisation has created the modern social, cultural, and political problems of the world. For example, it is blamed for increased competition. It ignores the fact that people in poorer countries need jobs. It encourages the production of goods for the world market, rather than being self-sufficient, and global jobs reduce unrest and increase stability. And, finally, interdependent economies mean less war. But the main problem is that the World Trade Organisation (WTO) makes the rules for globalisation, and globalisation is accelerating the exodus of manufacturing and white-collar jobs from countries.

Employment in the informal economy has generally increased around the world, and various forms of non-standard employment have emerged in most regions of the developed world. Global trade and investment patterns tend to benefit capital, especially companies that can move quickly and easily across borders, and to handicap labour, especially lowerskilled workers who cannot migrate easily, if at all [48]. To increase their global competitiveness, more and more investors are moving to countries that have low labour costs or shifting to informal employment arrangements. Globalisation also tends to benefit large companies that can capture new markets quickly and easily, to the detriment of small and micro entrepreneurs who face difficulties gaining knowledge of, let alone access to, emerging markets. In sum, globalisation puts pressure on low-skilled workers and small producers by weakening their bargaining power and subjecting them to increasing competition. But globalisation can also lead to new opportunities for those who work in the economy (formal or informal) in the form of new jobs in telecentres, homeworking, teleworking, e-working, mobile working, etc.

A few salient trends depict the globalisation of work: declining labour force participation ratios; a shift from employment in industry to employment in services; more precarious work; continuing or increasing youth unemployment; a decreasing labour share of national income; increasing wage differentiation; enterprises become transnational; production processes change; and migration [46].

Cowen [49] labelled 1990 as the decade of globalisation, but the year 2000 is considered to be glocalisation [50]. This term is defined by Friedman [51] as the ability of a culture to encounter other powerful cultures, to absorb influences that naturally fit into and can enrich that culture, to resist foreign affairs. We understand this term as a link between global and local in growth and diversity, without overwhelming them. Some authors regard glocalisation as the real path of globalisation [52]. Globalisation has increased the social space, leading to borderless economic, ecological, financial, social, political and cultural dimensions for traditional societies, driven by a world changing at an unprecedented rate. Stueckelberger [53] emphasises that "the technological and economic speed of globalization has to slow down a bit (decelerate) and the ethical, cultural and political globalization has to speed up substantially (accelerate)". Work flexibility

\section{Work flexibility}

The Industrial Revolution brought employees from their homes to the factories. With ICT, the reverse is possible, with employees now able to move back to their homes [54]. Employers give workers greater flexibility and liberate them from nine-to-five employment, thereby allowing them to work at any time in any place.

At present, workplace innovation refers to a number of specific actions, such as teleworking, telecommuting, remotework, networking, digital nomadic work, flexi-place, networking and many other variants [55-56], alternative payment schemes, employee empowerment and autonomy, task rotation, multi-skilling, teamwork and team autonomy. We believe that technology is an important enabler of workplace innovation. Increasing traffic congestion and the rise in the cost of petrol also makes flexible working conditions more appealing and less stressful to employees.

The flexibility for jobholders to be able to work at any time in any place is technically feasible for many employees and has been for many years. In the literature, the following seems to be an accepted category now: subject, working anywhere, for over forty years [57-59]. Workplace flexibility has been defined as an opportunity for workers to choose, with their choice influenced by when, where and for how long they will engage in work-related tasks [60] in a variety of forms.

Using technological innovations, more and more organisations have started to redesign their approach to work. We feel strongly that central to this new approach is the fact 
that employees are asked to organise their work flexibly. The ICT technologies provide the possibility for workers to be monitored; technology forms only one part of the management process. Managing these workers involves a significant amount of trust. This means that flexible working is an essential part of the future of work. The era when the man went to the office and the woman stayed at home has now long gone. As stated in the World Development Report 2012, women make up nearly $51.8 \%$ of participation in labour markets, while the male rate fell slightly from $82.0 \%$ to $77.7 \%$ [61].

The latest data from the Flexible working survey demonstrate that work flexibility is still a huge priority in our working life: $67 \%$ wish they had this opportunity, for $47 \%$ it is not encouraged, and $40 \%$ of people would choose it over a pay rise. Although $58 \%$ of workers are offered flexible working, $24 \%$ do not make use of it. A massive $70 \%$ of workers strongly believe that flexible working would make a job more attractive, and if employers plan to hire top talent, flexible working is an imperative. Among those in the survey, 58\% believe that working away from the office would help them to become more motivated, and 53\% think they would be more productive [62].

We have seen the importance that workplace flexibility has on attracting and retaining workers. Automation and digitisation will lead to a further shift in the workforce away from traditional work towards flexibility of work. The workday shift (the nine-to-five model) is becoming obsolete. Today's workforce is dynamic and diverse. Flexibility means better compatibility of private life, job and social responsibilities. Absenteeism could be reduced, the quality of life would rise, loyalty would increase and the economy could also profit from this.

\section{DISCUSSION AND CONCLUSIONS}

The future of work can mean anything that may be focused on different fundamental issues related to macro trends, the sharing economy, ecosystem, or social and personal transformation.

As we see it, the key attribute of the future of work is the time horizon. The time scale generally informs our vision of the future, and out of that the challenges, threats and opportunities arise. Relationships between individuals, employers, organisations and policymakers also develop over time; this means that work and society as a whole have changed over time and are continuing to do so. This raises a number of questions: If we believe that modern technology increases productivity, is the spread of flexibility also increasing? The next question is the relationship between modern work forms and health, and its impact on society. It seems likely that these will probably be renewed through a decrease of permanent employment contracts or an increase in the modern forms of flexible work.

Manyika [63] reviewed three aspects related to this discussion as follows: 1) the impact of artificial intelligence and automation on work and jobs, and whether we will have enough work and jobs left after that has run its course; 2) the changing models for work and work structure; and 3) whether any of those kinds of evolved work models will become the future, and whether people can work effectively and sustainably and earn sufficient living wages with enough support.

Technology is fundamentally a force for wealth creation in our lives. It is the reason we are always online, the mortality rates decrease, we have more leisure time, and we can work at any time in any place. The arguments in this study are that we can influence the future of work with these factors for the betterment of workers and the wider society.

Rather than make precise forecasts, we have argued for the existence of four major factors that will have an impact on the future, factors that will allow politicians and workers to prepare for a wide range of possible outcomes. The factors we have presented are not exhaustive in their portrayal of the way the world of work may change, but they are intended to be insightful and inspirational.

The question of what the nature of the new world of work will be and how we can shape it positively will always be a global issue. For example, the current flood of refugees worldwide shows us that a globally growing gap in living conditions (on the basis of income and security) is a worldwide problem. Furthermore, megatrends will increasingly show us that the problems of other countries are also our problems. We note that as a consequence of our four major factors the poorest countries of the world are expected to be affected more seriously than other countries. Above all, therefore, shaping the future of work requires a view that transcends national borders.

Each of the factors has distinct implications for the future of work. But the implications described require that action must be taken. To prepare employees for tomorrow's world of work, our study indicates four key areas for consideration by individuals, employees, employers, organisations and policymakers. The above discussion shows that all the following factors play an essential part in impacting on future work, namely technology, innovation, changes in society, globalisation and work flexibility. Therefore, we may assume that each of them has an important part to play in the overall impact.

Changes in technology (innovations) serve as another strong external influence on the structure of work and the content of jobs. The demographic characteristics of the labour force with increased diversity continue to evolve and change. Furthermore, climate forces cause and interact significantly with the restructuring of work. Flexibility at work has become more common and acceptable, with the advances of modern technology making it possible to work remotely and stay connected with the team.

Although some trends do appear to be dominant, it is still difficult to predict the future of work with any degree of certainty. The future of jobs will not be determined solely by the forces of technology, demographics, climate, globalisation and flexibility, but by the interaction of these forces with the strategies, missions, societal structures and policies that decision makers will implement. Nothing in the data we have 
examined supports the conclusion that the various changes in today's workplace will lead to the end of jobs in any sense. The conditions and the content of work are changing rapidly, but employment and labour-force participation remain, and modern forms of work are making their appearance. History has repeatedly shown that technology is killing jobs; our study shows that it is only technology can save them.

\section{REFERENCES}

[1] V. Burgmann, "The Strange Death of Labour History," Bede Nairn and Labor History, Sydney: Pluto Press, pp. 69-81, 1991.

[2] T. Irving, Challenges to Labour History, Sydney: University of New South Wales Press, 1994.

[3] C. J. Moody and A. Kessler-Harris, Perspectives on American Labor History - The Problems of Synthesis, DeKalb, IL: Northern Illinois University Press, 1989.

[4] M. Van der Linden, The End of Labour History?, Cambridge: Cambridge University Press, 1993.

[5] World Employment Confederation, The Future of Work. [Online] Available:

https://www.wecglobal.org/fileadmin/templates/ciett/docs/WEC__The _Future_of_Work_-_What_role_for_the_employment_industry.pdf. [Accessed: 24-September-2018].

[6] G. Wisskirchen et al. "Artificial Intelligence and Robotics and Their Impact on the Workplace," IBA Global Employment Institute, $120 \mathrm{pp}$. 2017.

[7] A. Smith and J. Anderson, AI, Robotics, and the Future of Jobs. [Online]. Available: http://www.fusbp.com/wpcontent/uploads/2010/07/AI-and-Robotics-Impact-on-Future-PewSurvey.pdf. [Accessed: 11-October-2019].

[8] C. B. Frey, and M. A. Osborne, "The future of employment: How susceptible are jobs to computerisation?" Technological Forecasting and Social Change, vol. 114 (C). pp. 1-72, 2013.

[9] C. B. Frey, and M. A. Osborne, "The future of employment. How susceptible are jobs to computerisation?" Technological Forecasting and Social Change, vol. 114 (C). pp. 254-280, 2017.

[10] C. B. Frey, and M. A. Osborne, Automation and the future of work, understanding the numbers. [Online]. Available: https://www.oxfordmartin.ox.ac.uk/blog/automation-and-the-future-ofwork-understanding-the-numbers/. [Accessed: 11-October-2019].

[11] ILO, World Employment Social Outlook, Trends 2019. [Online]. Available: https://www.ilo.org/wcmsp5/groups/public/---dgreports/--dcomm/---publ/documents/publication/wcms_670542.pdf. [Accessed: 11-October-2019].

[12] World Economic Forum, The Future of Jobs Report 2018. [Online]. Available:

http://www3.weforum.org/docs/WEF_Future_of_Jobs_2018.pdf. [Accessed: 11-October-2019].

[13] OECD, Future of Work and Skills. [Online]. Available: https://www.oecd.org/els/emp/wcms_556984.pdf. [Accessed: 25September-2018].

[14] I. Mandl, M. Curtarelli, S. Riso, O. Vargas LIave and E. Gerogiannis, New forms of employment. Eurofond, Luxembourg: Publications Office of the European Union, 2015.

[15] D., Gruen, Technological Change and the Future of Work. [Online]. Available: https://www.pmc.gov.au/news-centre/domesticpolicy/technological-change-and-future-work. [Accessed: 25September-2018].

[16] McKinsey Global Institute, Jobs Lost, Jobs Gained: Workforce transitions in a time of Automation. [Online]. Available: https://www.mckinsey.com/ /media/mckinsey/featured\%20insights/futu re\%20of\%20organizations/what $\% 20$ the $\% 20$ future $\% 20$ of $\% 20$ work $\% 20$ will $\% 20$ mean $\% 20$ for $\% 20$ jobs $\% 20$ skills $\% 20$ and $\% 20$ wages $/ \mathrm{mgi} \% 20$ jobs $\% 201$ ost-jobs\%20gained_report_december\%202017.ashx. [Accessed: 25-September-2018].

[17] I. Nübler, I. New technologies: A jobless future or golden age of job creation? International Labour Office, Research Department, Research Department working paper No. 13. - Geneva: ILO, ,2016.
[18] M. Ford, Attention White-Collar Workers: The Robots Are Coming For Your Jobs. [Online]. Available: https://www.npr.org/sections/alltechconsidered/2015/05/18/407648886/a ttention-white-collar-workers-the-robots-are-coming-for-your-jobs. [Accessed: 25-September-2018].

[19] Deloitte, Deloitte Insight, Over 100,000 legal roles to be automated. [Online]. Available: https://www.legaltechnology.com/latestnews/deloitte-insight-100000-legal-roles-to-be-automated/. [Accessed: 25-September-2018].

[20] I. Constantiou, A. Marton and V. K. Tuunainen, "Four Models of Sharing Economy Platforms“" MIS Quartely Executive, vol. 16 (4), pp. 231-251, 2017.

[21] A. Stephany, ALEX STEPHANY: HOW TO UNDERSTAND THE SHARING ECONOMY. [Online]. Available: https://www.lsnglobal.com/opinion/article/16302/alex-stephany-how-tounderstand-the-sharing-econom. [Accessed: 25-September-2018].

[22] K. Steinmetz, Exclusive: See How Big the Gig Economy Really is. [Online]. Available: http://time.com/4169532/sharing-economy-poll/. [Accessed: 25-September-2018]

[23] D. Selloni, "New Forms of Economies: Sharing Economy, Collaborative Consumption, Peer-to-Peer Economy,“ Springer International Publishing AG, CoDesign for Public-Interest Services, Research for Development, DOI 10.1007/978-3-319-53243-1_2, 2017.

[24] A, Stephany, The Business Sharing: Making it in the New Sharing Economy. Hampshire: Palgrave Macmillan, 2015.

[25] OECD, The Knowledge-Based Economy. [Online]. Available: https://www.oecd.org/sti/sci-tech/1913021.pdf. [Accessed: 25September-2018].

[26] W. W. Powell and K. Snellman, "The Knowledge Economy," Annual Review of Sociology, vol. 30, pp. 199-220, 2004

[27] Worldpopulationreview. [Online]. [Online]. Available: http://www.worldometers.info/world-population/. [Accessed: 25September-2018].

[29] CITI GPS, Global Perspectives \& Solutions: Technology at Work v2.0, The Future Is Not What It Used to Be. [Online]. Available: https://www.oxfordmartin.ox.ac.uk/downloads/reports/Citi_GPS_Techn ology_Work_2.pdf. [Accessed: 26-September-2018].

[30] H. Buck, E. Kistler and H. G. Mendius, Demograhic change in the world of work. Stuttgart: Bundesministerium für Bildung und Forschung, 2002.

[31] Ch. Grantham, Shifting the Paradigm From Wellness to Well-Being. [Online]. Available: https://workdesign.com/2018/02/shifting-theparadigm-from-wellness-to-wellbeing/. [Accessed: 26-September-2018].

[32] UN, About the Sustainable Development Goals. [Online]. Available: https://www.un.org/sustainabledevelopment/sustainable-developmentgoals/. [Accessed: 26-September-2018].

[33] T. H. P. Kowalski, W. Loretto, and T. Redman, "Call for papers: Special issue of international journal of human resource management: Wellbeing and HRM in the changing workplace," The International Journal of Human Resource Management, vol. 26, pp. 123-126, 2017.

[34] F. Luthans, F. and C. M. Youssef, "Human, social, and now positive psychological capital management: Investing in people for competitive advantage," Organizational Dynamics, vol. 33, pp. 143-160, 2004.

[35] M. Pasban,. And S. H. Nojedeh, "A Review of the Role of Human Capital in the Organization," Procedia Social and Behavioral Sciences, vol. 230, pp. 249-253, 2016.

[36] O. Richard, "Racial diversity, business strategy, and firm performance: A resource-based view," Academy of Management Journal, 43, pp. 164177, 2001.

[37] OECD, 21st Century Skills: Learning for the Digital Age. [Online]. Available: https://www.oecd-forum.org/users/50593-oecd/posts/2044221st-century-skills-learning-for-the-digital-age. [Accessed: 26September-2018].

[38] V. Hunt, D. Layton, and S. Prince, Why diversity matters. [Online]. Available: https://www.mckinsey.com/businessfunctions/organization/our-insights/why-diversity-matters. [Accessed: 26-September-2018].

[39] G. Graen and M. Grace, New Talent Strategy: Attract, Process, Educate, Empower, Engage and Retain the Best. [Online]. Available: https://www.shrm.org/hr-today/trends-and-forecasting/special-reports- 
and-expert-views/Documents/SHRM-

SIOP\%20New\%20Talent\%20Strategy.pdf. [Accessed: 26-September2018].

[40] J. M. Twenge, S. M. Campbell, B. J. Hoffman and C. E. Lance, "Generational differences in work values: Leisure and extrinsic values increasing, social and intrinsic values decreasing," Journal of Management, vol. 36, pp. 117-142, 2010.

[41] J. Blattner and T. J. Walter, "Creating and sustaining a highly engaged company culture in a multigenerational workplace," Strategic HR Review, vol. 14, pp. 124-130, 2015.

[42] OECD, OECD Environmental Outlook to 2050: The Consequences of Inaction. [Online]. Available: http://www.oecd.org/environment/indicators-modellingoutlooks/49846090.pdf. [Accessed: 26-September-2018].

[43] U. Huws, N. Jagger and S. O'Regan, Teleworking and Globalization. Bringhton: IES Report 358, 1999.

[44] ILO, Trade and Employment on Myths to Facts. [Online]. Available: http://www.ilo.org/wcmsp5/groups/public/--ed_emp/documents/publication/wcms_162297.pdf/. [Accessed: 26September-2018].

[45] A. McKeon, How the Globalization Cycle Could Impact HR and Your $\begin{array}{lll}\text { Organization. } & \text { [Online]. Available: }\end{array}$ https://www.adp.com/spark/articles/2017/10/how-the-globalizationcycle-could-impact-hr-and-your-organization.aspx\#. [Accessed: 26September-2018].

[46] R. Van der Hoeven, Globalization of Work, 2015 UNDP Human Development Report Office. [Online]. Available: na:http://hdr.undp.org/sites/default/files/van_der_hoeven_hdr_2015_fina 1.pdf. [Accessed: 26-September-2018].

[47] OECD, Globalization. [Online]. Available: https://stats.oecd.org/glossary/detail.asp?ID=1121. [Accessed: 26September-2018].

[48] D. Rodrik, Has Globalization Gone Too Far? Washington, D.C.: Institute for International Economics, 1997.

[49] T. Cowen, Creative Destruction: How Globalization is Changing the World's Cultures. Princenton, NJ: Princenton University Press, 2002.

[50] J. H. Westover, Globalization, Labor, and the Transformation of Work: Readings for Seeking a Competitive Advantage in an Increasingly Global Economy. IL: Common Ground Research Networks, 2010.

[51] T. L. Friedman, The Lexus and the Olive Tree. New York: Farrar, Straus Giroux, 1999.

[52] R. Robertson, Globalization -Social Theory and Global Culture. London: Sage Publications, 1992.

[53] Ch. Stueckelberger, Global Trade Ethics. An Illustrated Overview. Geneva: WCC Publications, 2002.

[54] S. Simitis, "The Juridification of Labour Relations," Comparative Labor Law, vol. 93. pp. 93-142, 1986.

[55] P. Bates, I. Bertin and U. Huws, E-Work in Ireland. Brighton: IES Report 394, 72 pp (2002).

[56] U. Huws, Statistical indicators of eWork, A Discussion paper. Brighton: IES, Report 385, 2001.

[57] J. M. Nilles, "Telecommunications and organizational decentralization. Communications," IEEE transactions on, vol. 23(10), pp. 1142-1147, 1975.

[58] R. B. Wilkes and M. N. Frolick, "Critical issues in developing successful tele-work programs," Journal of Systems Management, vol.45(7):30, 1994

[59] J. E. N. Hunton and C. Strand, "The impact of alternative telework arrangements on organizational commitment: Insights from a longitudinal field experiment," Journal of Information Systems, vol. 24(1), pp. 67-90, 2010.

[60] P. M. Bal and A. H. De Lange, ,'From flexibility human resource management to employee engagement and perceived job performance across the lifespan," In A multi-sample study' Journal of Occupational and Organisational Psychology, vol. 88, Issue 1: pp 126-154, 2014.

[61] The World Bank, World Development Report 2012, Gender Equality and Development. [Online]. Available: http://siteresources.worldbank.org/INTWDR2012/Resources/77781051299699968583/7786210-1315936222006/Complete-Report.pdf. [Accessed: 26-September-2018].
[62] Powwownow, Flexible Working in 2017. [Online]. Available: https://www.powwownow.co.uk/smarter-working/flexible-workingstatistics-2017. [Accessed: 26-September-2018].

[63] J. Manyika, What is the future of work? [Online]. Available: https://www.mckinsey.com/featured-insights/future-of-work/what-isthe-future-of-work. [Accessed: 28-September-2018]. 